\title{
Comparison of Outcomes for Patients Undergoing Balloon Angioplasty vs Coronary Stenting for Acute Myocardial Infarction Results From Nationwide Japanese Registry
}

\author{
Miyuki Tsuchihashi, MS; Hiroyuki Tsutsui, MD; Miwako Shihara, MD; \\ Hideo Tada, MD; Suminori Kono, MD*; Akira Takeshita, MD; \\ for the Japanese Coronary Intervention Study (JCIS) Group
}

\begin{abstract}
Randomized clinical trials have demonstrated that coronary stenting is more successful than balloon angioplasty in improving short- and long-term outcomes. However, it remains unknown whether those results can be generalized to broad-based practice. This study aimed to determine whether the outcome for patients with acute myocardial infarction (AMI) undergoing coronary stent placement would be better than those undergoing balloon angioplasty. The risk-adjusted mortality and subsequent revascularization rates were compared for 2,185 patients from a nationwide Japanese registry during 1997. A total of 1,349 patients were treated with balloon angioplasty alone and 836 had stent placement. There were no statistically significant differences in the prevalence of demographic, clinical, and angiographic variables, except that the angioplasty group had a greater proportion of female patients and those with a left circumflex lesion. Unadjusted in-hospital mortality was comparable ( 7.6 vs $6.3 \%$; $p=0.28$ ), despite higher angiographic success rate for the stent group (89.7 vs $97.7 \% ; \mathrm{p}<0.01)$. Adjusted odds ratio for inhospital mortality was $0.75(\mathrm{p}=0.19)$. The same-admission bypass surgery rate was also similar. The 1.9 -year post-discharge mortality rate was similar. The need for subsequent revascularization procedures was also similar, but restenosis was significantly lower in the stent group (34 vs $45 \%$; $p<0.01$ ). The superiority of clinical outcome for stenting rather than balloon angioplasty could not be demonstrated in broad-based registry patients, despite technically successful results. (Circ J 2003; 67: 369-374)
\end{abstract}

Key Words: Acute myocardial infarction; Coronary intervention; In-hospital mortality; Long-term mortality

$\mathbf{T}$ he efficacy of percutaneous coronary intervention (PCI) has been established for the treatment of patients with acute myocardial infarction (AMI),, 2 and there is now increasing evidence from randomized trials that coronary stent placement yields significantly better results than balloon angioplasty ${ }^{3-8}$ However, there is scant information available from routine clinical practice to determine the effects of stents on short- and long-term outcome. As in many randomized controlled studies, these trials included only a small proportion of selected patients, and the hospitals participating in the trials are particularly experienced and large-volume centers. In fact, previous subgroup analyses using the registry data from New York ${ }^{9}$ and Germany ${ }^{10}$ and a retrospective analysis of a single institution's data, 11 could not observe a significant improvement in clinical outcomes in AMI patients receiving coronary stents. In contrast, a recent report from Veterans Affairs'

(Received December 2, 2002; revised manuscript received February 21, 2003; accepted February 27, 2003)

Departments of Cardiovascular Medicine and *Preventive Medicine, Graduate School of Medical Sciences, Kyushu University, Fukuoka, Japan

The members of the Japanese Coronary Intervention Study (JCIS) Group are listed in the Appendix.

Mailing address: Hiroyuki Tsutsui, MD, PhD, Department of Cardiovascular Medicine, Graduate School of Medical Sciences, Kyushu University, 3-1-1 Maidashi, Higashi-ku, Fukuoka 812-8582, Japan.

E-mail: prehiro@cardiol.med.kyushu-u.ac.jp medical centers indicated that stent placement was associated with better short- and long-term outcomes!2 Therefore, it has not been explicitly clarified whether the results of randomized trials apply to the 'real world' of broad-based practice. To justify the use of coronary stents, one must quantify the effects of coronary stenting in actual clinical practice.

Therefore, the purpose of this study was to compare the early (in-hospital) and long-term (1.9 year) follow-up data from patients with AMI who had undergone PCI with either balloon angioplasty or stent placement. The Japanese Coronary Intervention Study (JCIS) is an extensive nation-wide survey of practice in Japan, ${ }^{13-15}$ designed to accumulate information on contemporary broad-based clinical practice. We analyzed not only mortality, but also the incidence of revascularization procedures, including repeat PCI and coronary artery bypass grafting $(\mathrm{CABG})$, during follow-up.

\section{Methods}

\section{Patient Population}

Patient selection and data collection have been described previously 13,15 Briefly, the JCIS survey demonstrated that 109,788 PCI procedures were performed at 1,023 hospitals during 1997 in Japan. The patients' characteristics and outcomes were evaluated in a total of randomly selected 10,642 PCIs, which represented approximately $10 \%$ of all PCIs registered in the JCIS. All patients with AMI $(\mathrm{n}=$ 2,540 ) who had undergone PCI were identified. Inclusion 
criteria were patients with AMI who presented within $6 \mathrm{~h}$ of symptom onset, or between 6 and $24 \mathrm{~h}$ if they had persistent symptoms with evidence of ongoing ischemia, including chest pain and ST-segment elevation in the infarct region. Patients in whom PCI was interrupted during the procedure $(n=20)$ and those with an incomplete data set regarding the infarct-related artery $(n=306)$ and in-hospital complications $(n=3)$ were excluded. Further exclusions were patients who underwent other PCIs such as atherectomy or laser angioplasty in addition to balloon angioplasty or stent placement $(n=12)$. Patients who had more than one lesion attempted were also excluded $(n=14)$ because it was impossible to determine whether balloon angioplasty or stent placement was the only intervention attempted on all lesions. This approach led to the identification of 2,185 patients, 1,349 of whom underwent balloon angioplasty and 836 of whom underwent stent placement. For each patient, baseline demographic information, clinical factors, angiographic findings, procedural data, in-hospital and long-term outcomes were collected by the investigators in each institution.

\section{Data Collection}

The patients' demographic information, cardiovascular history, their risk factors (ie, hypercholesterolemia, smoking, hypertension, and diabetes mellitus) were recorded. Hypercholesterolemia was defined as total cholesterol $\geq 220 \mathrm{mg} / \mathrm{dl}$; hypertension was defined as systolic blood pressure $>140 \mathrm{mmHg}$ and/or diastolic blood pressure $>90 \mathrm{mmHg}$; diabetes mellitus was defined as fasting blood sugar $\geq 140 \mathrm{mg} / \mathrm{dl}$ or blood sugar during a $75 \mathrm{~g}$ oral glucose tolerance test $\geq 200 \mathrm{mg} / \mathrm{dl}$; renal failure was defined as serum creatinine $\geq 2.5 \mathrm{mg} / \mathrm{dl}$. Single-vessel disease was defined as $\geq 51 \%$ stenosis in any of the major coronary arteries or their major branches, and multivessel disease was defined as $\geq 51 \%$ stenosis in either 2 or all 3 major epicardial coronary arteries. Further, the left ventricular ejection fraction (LVEF) was assessed by any method including left ventricular (LV) angiography, echocardiography, and radionuclide angiography, and categorized as (1) $\geq 50 \%$ and (2) $<50 \%$ or unknown.

\section{Outcome}

Follow-up data were obtained by reviewing the medical records and/or mail or telephone contact with the patients 15 We assessed death and the use of revascularization procedures including repeat $\mathrm{PCI}$ and $\mathrm{CABG}$ during and after the

Table 1 Characteristics fo the Patients Treated With Balloon Angioplasty vs Those With Stent Placement

\begin{tabular}{|c|c|c|c|}
\hline & Angioplasty $(n=1,349)$ & Stent $(n=836)$ & $p$ value \\
\hline Age (mean $\pm S D$, years) & $65.1 \pm 11.5$ & $64.8 \pm 11.1$ & 0.29 \\
\hline$\geq 75$ year $(\%)$ & 22.2 & 19.9 & 0.19 \\
\hline Male (\%) & 73.1 & 77.3 & 0.03 \\
\hline Prior myocardial infarction (\%) & 2.0 & 2.0 & 0.96 \\
\hline Hypercholesterolemia (\%) & 36.5 & 37.1 & 0.81 \\
\hline Smoking (\%) & 51.8 & 54.0 & 0.14 \\
\hline Hypertension (\%) & 50.8 & 49.9 & 0.66 \\
\hline Diabetes mellitus (\%) & 28.8 & 27.4 & 0.41 \\
\hline Renal failure (\%) & 2.0 & 1.7 & 0.58 \\
\hline Cerebrovascular disease (\%) & 8.4 & 8.0 & 0.68 \\
\hline Prior PCI (\%) & 5.4 & 5.5 & 0.94 \\
\hline Prior $C A B G(\%)$ & 0.6 & 0.7 & 0.73 \\
\hline \multicolumn{4}{|l|}{ Affected coronary artery (\%) } \\
\hline Left anterior descending & 50.3 & 52.0 & 0.42 \\
\hline Right & 34.8 & 37.7 & 0.18 \\
\hline Left circumflex & 13.9 & 8.9 & $<0.01$ \\
\hline Left main & 1.0 & 1.4 & 0.31 \\
\hline \multicolumn{4}{|l|}{ No of diseased vessels (\%) } \\
\hline Single vessel & 60.6 & 60.5 & 0.97 \\
\hline Multivessel & 37.5 & 37.0 & 0.88 \\
\hline Left main & 1.9 & 2.5 & 0.37 \\
\hline Ejection fraction (mean $\pm S D, \%$ ) & $55.0 \pm 14.0$ & $54.4 \pm 14.0$ & 0.92 \\
\hline$\geq 50 \%(\%)$ & 48.9 & 45.7 & 0.14 \\
\hline
\end{tabular}

PCI, percutaneous coronary intervention; $C A B G$, coronary artery bypass grafting.

Table 2 Unadjusted and Adjusted Odds Ratio (OR) of In-Hospital Outcomes for Patients Treated With Balloon Angioplasty vs Those With Stent Placement

\begin{tabular}{|c|c|c|c|c|}
\hline \multirow[b]{2}{*}{ Outcome } & \multicolumn{2}{|c|}{ Number (\%) } & \multirow[b]{2}{*}{$\begin{array}{l}\text { Unadjusted OR } \\
\quad(95 \% \text { CI) }\end{array}$} & \multirow[b]{2}{*}{$\begin{array}{l}\text { Adjusted OR } \\
(95 \% \text { CI) }\end{array}$} \\
\hline & $\begin{array}{c}\text { Angioplasty } \\
(n=1,349)\end{array}$ & $\begin{array}{c}\text { Stent } \\
(n=836)\end{array}$ & & \\
\hline In-hospital mortality & $102(7.6 \%)$ & $53(6.3 \%)$ & $\begin{array}{c}0.83(0.59-1.17) \\
p=0.28\end{array}$ & $\begin{array}{c}0.75(0.49-1.16) \\
p=0.19\end{array}$ \\
\hline Repeat PCI & $42(3.1 \%)$ & $34(4.1 \%)$ & $\begin{array}{c}1.32(0.83-2.10) \\
p=0.24\end{array}$ & $\begin{array}{c}1.29(0.81-2.06) \\
p=0.28\end{array}$ \\
\hline$C A B G$ & $13(1.0 \%)$ & $8(1.0 \%)$ & $\begin{array}{c}0.99(0.41-2.41) \\
p=0.99\end{array}$ & $\begin{array}{c}0.91(0.35-2.34) \\
p=0.84\end{array}$ \\
\hline Angiographic success & $1210(89.7 \%)$ & $817(97.7 \%)$ & $\begin{array}{c}0.20(0.12-0.33) \\
p<0.0001\end{array}$ & $\begin{array}{c}0.23(0.12-0.45) \\
p<0.0001\end{array}$ \\
\hline
\end{tabular}

PCI, percutaneous coronary intervention; $C A B G$, coronary artery bypass grafting; $C I$, confidence interval. 
hospitalization.

Angiographic success was defined as successful dilation to $\leq 50 \%$ residual stenosis or Thrombolysis in Myocardial Infarction (TIMI) grade 3 flow of the attempted lesions. Restenosis was defined as a final stenosis $>50 \%$ at followup or a loss of at least $50 \%$ of the gain in luminal diameter achieved by PCI.

In-hospital follow-up data were collected for all patients. Long-term follow-up data were obtained in 1,914 of 2,030 discharged patients $(94.3 \%)$. The mean follow-up interval was approximately 1.9 years in both groups $(697 \pm 174$ days for the angioplasty group and $699 \pm 179$ days for the stent group; $\mathrm{p}=0.808$ ).

\section{Statistical Analysis}

Patient characteristics and outcomes were compared between the angioplasty and stent groups; chi-square statistic was used for categorical variables and unpaired $t$ test for continuous variables. As for in-hospital outcomes, odds ratios (OR) for patients treated with balloon angioplasty as compared with stenting were calculated by logistic regression analysis. Long-term outcomes in the 2 groups were examined by Kaplan-Meier curves, and Cox's proportionalhazards models were used to calculate relative risk. Adjustment was made for variables potentially associated with treatment selection including age, gender, previous MI, hypercholesterolemia, smoking, hypertension, diabetes mellitus, renal failure, cerebrovascular disease, prior PCI, prior $\mathrm{CABG}$, attempted lesion, number of diseased vessels, and LVEF. Both short- and long-term outcomes were also compared for angioplasty vs stenting within subgroups classified by the baseline characteristics: number of diseased vessels, proximal left anterior descending (LAD) disease, diabetes mellitus, and normal/abnormal LVEF. Statistical analyses were performed by using the SAS (version 8.1), and a two-sided $\mathrm{p}$ value less than 0.05 was regarded as statistically significant.

\section{Results}

Patient characteristics including demographic data, medical history, risk factors, and angiographic data are shown in Table 1. As noted, patients treated by balloon angioplasty were less often males and were more likely to have had a left circumflex coronary artery lesion than patients treated by stents. There were no significant differences in other variables between the 2 groups of patients.

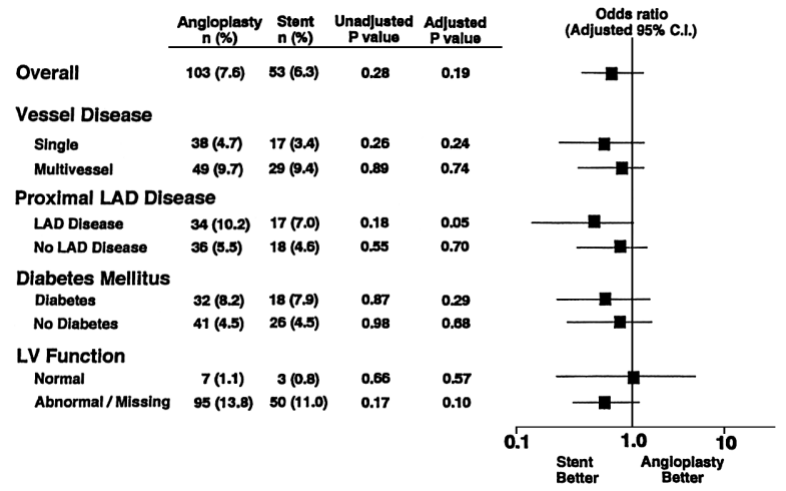

Fig 1. Odds ratios for in-hospital mortality with confidence intervals (CI) for balloon angioplasty versus stents were obtained from logistic regression analysis models comparing balloon angioplasty and stents with adjustment for all variables for the entire group and within each of the specified subgroups. LAD, left anterior descending coronary artery. LV, left ventricle.

Even though the rate of angiographic success was higher in the stent group ( 89.7 vs $97.7 \%$, p<0.0001), the in-hospital mortality rate was comparable ( 7.6 vs $6.3 \%$ ) between the balloon angioplasty and stent groups (Table 2). Even after adjustment for all potentially confounding factors, the risk of in-hospital mortality was similar (OR 0.75). The adjusted rates of need for repeat PCI or CABG during the hospitalization were also comparable between the 2 groups. Fig 1 shows the adjusted OR for in-hospital mortality for 8 subgroups of patients: single and multivessel disease, proximal LAD and non-LAD disease, diabetes and nondiabetes, and normal and abnormal or missing LV function data. Inhospital mortality was comparable in all subgroups that were examined. Even though the in-hospital mortality in the stent group tended to be lower in the subgroup of proximal LAD disease $(10.2$ vs $7.0 \%)$, this difference did not reach statistical significant $(\mathrm{p}=0.053)$.

Despite the benefits of stents in reducing restenosis (44.5 vs $34.2 \%, \mathrm{p}<0.0001)$, they were not associated with a statistically significant reduction in long-term outcomes including all cause mortality, cardiac mortality, or the need for revascularization procedures (Table 3 ). All results were essentially unchanged even after adjustment for all potentially confounding variables. Fig 2 represents the 1.9-year adjusted mortality curves for the angioplasty and stent groups. As indicated, the cumulative adjusted mortality

Table 3 Unadjusted and Adjusted Relative Risk (RR) of Long-Term Outcomes for Patients Treated With Balloon Angioplasty vs Those With Stent Placement

\begin{tabular}{|c|c|c|c|c|}
\hline \multirow[b]{2}{*}{ Outcome } & \multicolumn{2}{|c|}{ Number (\%) } & \multirow[b]{2}{*}{$\begin{array}{l}\text { Unadjusted RR } \\
\quad(95 \% \text { CI) }\end{array}$} & \multirow[b]{2}{*}{$\begin{array}{l}\text { Adjusted RR } \\
(95 \% \text { CI) }\end{array}$} \\
\hline & $\begin{array}{c}\text { Angioplasty } \\
(n=1,171)\end{array}$ & $\begin{array}{c}\text { Stent } \\
(n=836)\end{array}$ & & \\
\hline All-cause mortality & $69(5.9 \%)$ & $47(6.3 \%)$ & $\begin{array}{c}1.09(0.75-1.58) \\
p=0.65\end{array}$ & $\begin{array}{c}1.07(0.73-1.58) \\
p=0.71\end{array}$ \\
\hline Cardiac mortality & $25(2.1 \%)$ & $26(3.5 \%)$ & $\begin{array}{c}1.63(0.94-2.83) \\
p=0.08\end{array}$ & $\begin{array}{c}1.57(0.88-2.80) \\
p=0.12\end{array}$ \\
\hline Repeat PCI & $417(35.6 \%)$ & $267(35.9 \%)$ & $\begin{array}{c}1.00(0.86-1.17) \\
p=1.00\end{array}$ & $\begin{array}{c}0.99(0.85-1.16) \\
p=0.96\end{array}$ \\
\hline$C A B G$ & $77(6.6 \%)$ & $51(6.9 \%)$ & $\begin{array}{c}1.04(0.73-1.49) \\
p=0.81\end{array}$ & $\begin{array}{c}1.01(0.70-1.47) \\
p=0.93\end{array}$ \\
\hline Restenosis & $427(44.5 \%)$ & $220(34.2 \%)$ & $\begin{array}{c}0.65(0.53-0.80) \\
p<0.0001\end{array}$ & $\begin{array}{c}0.63(0.52-0.78) \\
p<0.0001\end{array}$ \\
\hline
\end{tabular}

PCI, percutaneous coronary intervention; $C A B G$, coronary artery bypass grafting; CI, confidence interval. 


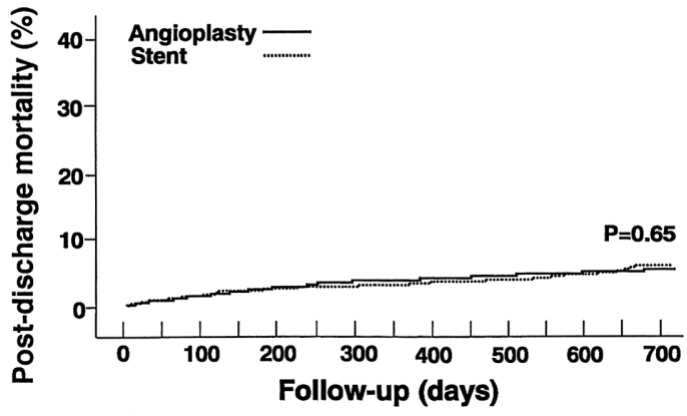

Fig 2. Kaplan-Meier analysis of 1.9-year post-discharge mortality for patients having balloon angioplasty (solid line) or stent placement (dashed line).

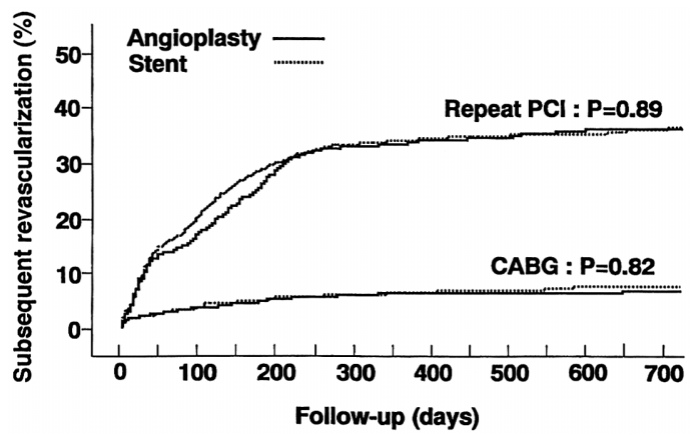

Fig 3. Kaplan-Meier analysis of the need for repeat PCI and CABG for patients having balloon angioplasty (solid line) or stent placement (dashed line).

rates were similar. In addition to mortality rates, the requirement for repeat PCI or CABG was also similar (Fig 3). Fig 4 shows the adjusted mortality relative risks for longterm mortality for balloon angioplasty and stent placement for 8 subgroups of patients as shown in Fig1. Again, adjusted post-discharge mortality rates were comparable in all subgroups analyzed.

\section{Discussion}

The present study demonstrated that stent placement did not significantly reduce the risk of in-hospital mortality and the need for subsequent revascularization compared with balloon angioplasty in patients with AMI despite a significantly higher angiographic success. Further, stents reduced the incidence of restenosis of the infarcted coronary artery, but did not affect the long-term mortality and the need for revascularization procedures including repeat $\mathrm{PCI}$ or $\mathrm{CABG}$ after discharge.

Previous randomized clinical trials comparing balloon angioplasty with stent placement in the treatment of patients with AMI have demonstrated improved short- and long-term outcomes in the stent-treated patients ${ }^{3-8}$ In contrast, the present study analyzing broad-based registry patients with AMI could not demonstrate any benefits in coronary stenting compared with balloon angioplasty.

There are several explanations for the lack of a beneficial relationship between stents and clinical outcomes. First, this is not a randomized clinical trial. Consequently, the choice of treatment was influenced by the attending physician's decision. It is possible that patients receiving stents were at higher risk of cardiac events, therefore making a

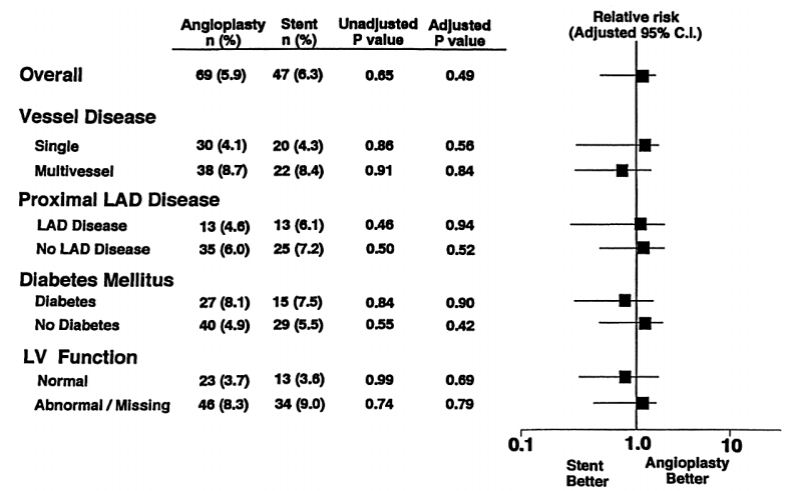

Fig 4. Relative risks for long-term mortality with confidence intervals (CI) for balloon angioplasty versus stents were obtained from multivariate Cox's proportional-hazards models comparing balloon angioplasty and stents with adjustment for all variables for the entire group and within each of the specified subgroups. LAD, left anterior descending coronary artery. LV, left ventricle.

truly beneficial effect of stenting. In fact, there was a small, although statistically insignificant, excess of patients with left main disease ( 1.0 vs $1.4 \%, \mathrm{p}=0.31)$ in the stent group (Table 1). In addition, more patients with a left circumflex lesion were treated with balloon angioplasty (13.9 vs $8.9 \%$, $\mathrm{p}<0.01)$ and this group of patients might have had a reasonably good prognosis $!^{1}$ However, the 2 patient groups were quite similar with respect to preprocedural risk factors. Furthermore, we attempted to minimize the treatment selection bias by adjusting the differences among patients in the prevalence of potentially confounding demographic, clini$\mathrm{cal}$, and angiographic variables. Therefore, uncontrolled confounding is unlikely to explain the results. Despite this, it cannot be excluded that patients undergoing stent placements might have had clinical signs of severity that escaped the usual clinical description taken into account in the present study. Second, stents used as bailout therapy for abrupt closure (not discernible from the data set in this study) might increase the risk of adverse outcomes in the stent group ${ }^{16}$ Third, the design of the present study could result in a failure to detect a reduction in risk from stents because of chance. However, the consistency of the lack of benefit in the different subgroups suggests that these findings were not from chance. Fourth, an even higher risk for in-hospital adverse outcomes with coronary stenting compared with balloon angioplasty has been shown,${ }^{17}$ and might be related to slower antegrade flow after stenting 18 which is at least partly attributable to thrombus formation at the site of stent implantation followed by distal embolization 19 Therefore, stenting might have reduced epicardial flow, which would have adversely affected the in-hospital outcomes in the present study. Whatever the reason, the present findings are consistent with those obtained from the New York ${ }^{9}$ and German registries, ${ }^{10}$ which both found that there was not a short- or long-term outcome benefit for stent placement in patients with AMI. The similarities between those 2 registries and ours are striking, and are also supported by a recent retrospective analysis of patients with AMI treated with PCI.1 Given the larger sample sizes, registry data can be an important supplement to randomized clinical trial data.

The present study demonstrated that stents reduced the incidence of restenosis, but not the need for revascularization (Table 3). Even though the angiographic findings, such 
as reference coronary artery diameter and minimal luminal diameter, were not available for the present study, there are several potential explanations for this finding. First, more of the patients treated with balloon angioplasty might not have undergone revascularization despite the occurrence of angiographic restenosis. Second, the diameter of stents might have been too small and the inflation pressure might have been too low, which would increase the rate of restenosis in the stent-treated patients.

In considering the findings between randomized trials and observational studies, one has to keep in mind that the patient population in randomized multicenter clinical trials may be a selected group of patients with a low risk profile compared with the large-scale observational studies from a more diverse range of hospitals and patients. Recently, it has been postulated that the same selection bias contributes to the differences in the results between randomized controlled studies ${ }^{20,21}$ and nonrandomized, observational studies comparing thrombolysis with primary angioplasty?2 Registries can document the relationship between therapeutic modalities used in the real world and clinical outcomes, despite their methodological biases; in particular the comparability of different groups of patients receiving different treatments. Therefore, further evaluation is needed before we can definitively recommend routine stent placement as the standard care for patients with AMI.

\section{Study Limitations}

First, important angiographic variables, such as target lesion morphology, as well as clinical variables, such as cardiogenic shock, heart failure and antecedent thrombolytic therapy, were not included in the present study. In addition, the lack of information on medications, such as $\beta$-blockers, angiotensin-converting enzyme inhibitors and statins, is also a potential limitation. These variables should be included in the future registry. Second, the present study was performed before platelet glycoprotein $\mathrm{IIb} / \mathrm{III} \mathrm{a}$ inhibitors were available in Japan. Previous studies reported more cardiac events with stent placement and argued that stenting might actually increase risk in the absence of glycoprotein IIb/IIIa inhibitors? 23,24 The introduction of glycoptrotein $\mathrm{IIb} / \mathrm{III} a$ receptor inhibitors into PCI practice may improve immediate clinical outcome as well as reduce the requirement for repeat PCI. However, the limitation of the inclusion of patients in the era before glycoprotein IIb/IIIa inhibitors does have the advantage of permitting the present study to examine the effects of stenting independent of the effects of these drugs. Third, the practice of interventional cardiology continues to change with improvements in stent design, increasing experience of cardiologists with the techniques, and more appropriate use of adjunct pharmacotherapy. Therefore, continual assessment of progress in the evolution of PCI is essential.

\section{Conclusions}

Stent placement in the present broad-based cohort of patients with AMI did not show superior short- or long-term clinical outcomes compared with balloon angioplasty.

\section{Acknowledgments}

This survey could not have been carried out without the help, cooperation and support of the cardiologists and cardiac surgeons in the survey institutions. We thank the participating cardiologists for allowing us to obtain the data. This work was supported by Health Sciences Research
Grants (Research on Health Services) from the Japanese Ministry of Health, Labour and Welfare (\#10150305) and Japan Arteriosclerosis Prevention Fund.

\section{References}

1. Grines CL, Browne KF, Marco J, Rothbaum D, Stone GW, O'Keefe $\mathrm{J}$, et al. A comparison of immediate angioplasty with thrombolytic therapy for acute myocardial infarction: The Primary Angioplasty in Myocardial Infarction Study Group. N Engl J Med 1993; 328: 673 679.

2. de Boer MJ, Suryapranata H, Hoorntje JC, Reiffers S, Liem AL, Miedema K, et al. Limitation of infarct size and preservation of left ventricular function after primary coronary angioplasty compared with intravenous streptokinase in acute myocardial infarction. Circulation 1994; 90: $753-761$.

3. Stone GW, Brodie BR, Griffin JJ, Morice MC, Costantini C, St Goar FG, et al. Prospective, multicenter study of the safety and feasibility of primary stenting in acute myocardial infarction: In-hospital and 30-day results of the PAMI stent pilot trial: Primary Angioplasty in Myocardial Infarction Stent Pilot Trial Investigators. J Am Coll Cardiol 1998; 31: 23-30.

4. Antoniucci D, Santoro GM, Bolognese L, Valenti R, Trapani M, Fazzini PF. A clinical trial comparing primary stenting of the infarctrelated artery with optimal primary angioplasty for acute myocardial infarction: Results from the Florence Randomized Elective Stenting in Acute Coronary Occlusions (FRESCO) trial. J Am Coll Cardiol 1998; 31: $1234-1239$.

5. Suryapranata H, van't Hof AW, Hoorntje JC, de Boer MJ, Zijlstra F. Randomized comparison of coronary stenting with balloon angioplasty in selected patients with acute myocardial infarction. Circulation 1998; 97: 2502-2505.

6. Rodriguez A, Bernardi V, Fernandez M, Mauvecin C, Ayala F, Santaera O, et al. In-hospital and late results of coronary stents versus conventional balloon angioplasty in acute myocardial infarction (GRAMI trial): Gianturco-Roubin in Acute Myocardial Infarction. Am J Cardiol 1998; 81: 1286-1291.

7. Grines CL, Cox DA, Stone GW, Garcia E, Mattos LA, Giambartolomei A, et al. Coronary angioplasty with or without stent implantation for acute myocardial infarction: Stent Primary Angioplasty in Myocardial Infarction Study Group. N Engl J Med 1999; 341: $1949-1956$.

8. Stone GW, Grines CL, Cox DA, Garcia E, Tcheng JE, Griffin JJ, et al. Comparison of angioplasty with stenting, with or without abciximab, in acute myocardial infarction. $N$ Engl J Med 2002; 346: 957-966.

9. Hannan EL, Racz MJ, Arani DT, Ryan TJ, Walford G, McCallister BD. Short- and long-term mortality for patients undergoing primary angioplasty for acute myocardial infarction. J Am Coll Cardiol 2000; 36: $1194-1201$.

10. Vogt A, Niederer W, Pfafferott C, Engel HJ, Heinrich W, Merx W, et al. Direct percutaneous transluminal coronary angioplasty in acute myocardial infarction: Predictors of short-term outcome and the impact of coronary stenting: Study Group of The Arbeitsgemeinschaft Leitender Kardiologischer Krankenhausarzte (ALKK). Eur Heart J 1998; 19: 917-921.

11. Bar F, Vainer J, Stevenhagen J, Neven K, Aalbregt R, Ophuis TO, et al. Ten-year experience with early angioplasty in 759 patients with acute myocardial infarction. J Am Coll Cardiol 2000; 36: 51-58.

12. Maynard C, Wright SM, Every NR, Ritchie JL. Comparison of outcomes of coronary stenting versus conventional coronary angioplasty in the Department of Veterans Affairs medical centers. Am J Cardiol 2001; 87: 1240-1245.

13. Shihara M, Tsutsui H, Tsuchihashi M, Shigematsu H, Yamamoto $S$, Koike G, et al. Coronary revascularization in Japan. Part 1: Survey of facilities during 1997. Jpn Circ J 2001; 65: 1005-1010.

14. Tsuchihashi M, Tsutsui H, Shihara M, Shigematsu H, Yamamoto S, Koike G, et al. Coronary revascularization in Japan. Part 2: Comparison of facilities between 1997 and 1999. Jpn Circ J 2001; 65: 1011 1016.

15. Shihara M, Tsutsui $H$, Tsuchihashi M, Shigematsu H, Yamamoto $S$, Koike G, et al. Coronary revascularization in Japan. Part 3: Percutaneous coronary intervention during 1997. Circ J 2002; 66: 10-19.

16. Piana RN, Ahmed WH, Chaitman B, Ganz P, Kinlay S, Strony J, et al. Effect of transient abrupt vessel closure during otherwise successful angioplasty for unstable angina on clinical outcome at six months: Hirulog Angioplasty Study Investigators. J Am Coll Cardiol 1999; 33: 73-78.

17. Serruys PW, van Hout B, Bonnier H, Legrand V, Garcia E, Macaya $\mathrm{C}$, et al. Randomised comparison of implantation of heparin-coated stents with balloon angioplasty in selected patients with coronary 
artery disease (Benestent II). Lancet 1998; 352: 673-681.

18. Wakatsuki T, Nakamura M, Tsunoda T, Toma H, Degawa T, Oki T, et al. Coronary flow velocity immediately after primary coronary stenting as a predictor of ventricular wall motion recovery in acute myocardial infarction. J Am Coll Cardiol 2000; 35: 1835-1841.

19. Erbel R, Heusch G. Coronary microembolization: Its role in acute coronary syndromes and interventions. Herz 1999; 24: 558-575.

20. Every NR, Parsons LS, Hlatky M, Martin JS, Weaver WD. A comparison of thrombolytic therapy with primary coronary angioplasty for acute myocardial infarction: Myocardial Infarction Triage and Intervention Investigators. $N$ Engl J Med 1996; 335: 1253-1260.

21. Nunn CM, O'Neill WW, Rothbaum D, Stone GW, O'Keefe J, Overlie $\mathrm{P}$, et al. Long-term outcome after primary angioplasty: Report from the primary angioplasty in myocardial infarction (PAMI-I) trial. J Am Coll Cardiol 1999; 33: 640-646.

22. Danchin N, Vaur L, Genes N, Etienne S, Angioi M, Ferrieres J, et al. Treatment of acute myocardial infarction by primary coronary angioplasty or intravenous thrombolysis in the 'real world': One-year results from a nationwide French survey. Circulation 1999; 99: $2639-2644$

23. Serruys PW, de Jaegere P, Kiemeneij F, Macaya C, Rutsch W, Heyndrickx G, et al. A comparison of balloon-expandable-stent implantation with balloon angioplasty in patients with coronary artery disease: Benestent Study Group. N Engl J Med 1994; 331: 489-495.

24. Topol EJ. Coronary-artery stents: Gauging, gorging, and gouging. $N$ Engl J Med 1998; 339: 1702-1704.

\section{Appendix 1}

The members of the Japanese Coronary Intervention Study (JCIS) Group.
Principal Investigator: Akira Takeshita (Kyushu University).

Co-investigators: Hisayoshi Fujiwara (Gifu University, The Japanese Circulation Society); Toshiyuki Noda (Gifu University); Kazuhiko Nishigaki (Gifu University); Atsuko Ohno (Gifu University); Akira Furuse (JR Tokyo General Hospital, The Japanese Society for Cardiovascular Surgery); Katsuo Kanmatsuse (Nihon University, The Japanese Coronary Association); Ikuyoshi Watanabe (Nihon University); Hitoshi Koyanagi, (Tokyo Women's Medical University, The Japanese Association for Thoracic Surgery); Hiroshi Nishida (Tokyo Women's Medical University); Osamu Iimura (The Japanese Association for CerebroCardiovascular Disease Control); Kazuo Ueda (Kyushu University, The Japanese Association for Cerebro-Cardiovascular Disease Control); Hiroshi Yamaguchi (Juntendo University, The Japanese Coronary Association); Tetsu Yamaguchi (Toho University, The Japanese Society of Interventional Cardiology); Yoshio Yazaki, (International Medical Center of Japan, The Japanese Circulation Society); Junichi Yoshikawa (Osaka City University, The Japanese College of Cardiology); Ken-ei Shimada (Osaka City University); Akira Kitabatake (Hokkaido University); Kazushi Urasawa (Hokkaido University); Hitonobu Tomoike, (Yamagata University); Isao Kubota (Yamagata University); Noboru Takekoshi (Kanazawa Medical University); Michihiko Kitayama, (Kanazawa Medical University); Masunori Matsuzaki (Yamaguchi University); Takashi Fujii(Yamaguchi University); Suminori Kono (Kyushu University).

Data Management and Analysis: Hiroyuki Tsutsui, Miwako Shihara, Miyuki Tsuchihashi, Hideaki Shigematsu, Hideo Tada, Hiroaki Shimokawa, Hikaru Ueno, Kensuke Egashira, Masahiro Mohri, Yuichi Ohara, Shinji Sato, Yoshitaka Hirooka, George Koike, Toshihiro Ichiki, Toru Kubota, and Yoji Hirakawa (Kyushu University).

Coordinators: Kaori Imanara, Yukiko Matsuo, and Yoko Komiya (Kyushu University). 